\title{
Effects of physicochemical properties of different substrates on characters and yield of maize
}

\author{
Xuejiao Ren, Jiabin Ci, Liangyu Jiang, Weiguang Yang, Wei Yang* \\ Faculty of Agronomy, Jilin Agricultural University, Changchun 130118, China
}

\section{A B S T R A C T}

\begin{abstract}
A reasonable method was used to analyze the effects of different substrates on the characters and yield of maize, and to improve the quality and yield of maize. The effects of the maize characters and yield of national Fluvo-aquic soil fertility and fertilizer efficiency monitoring base were analyzed from 6 aspects: fertilization and combined application, fertilization and density coupling, controlled release fertilizer (CRF), fertilization level, fertilization depth and proportion, and the amount of organic manure (chicken manure). Data processing is done by using Excel2003 and SPSS17.0 software, and multiple comparisons are made by using Duncan's new multiple range test method. The experiment of the influence factor of fertilization and combined application shows that the combination of NPK + organic fertilizer (constant and high) can increase maize character ratio and NPK + high-amount organic manure can increase maize yield. The experiment of the influence factor of fertilization and density coupling shows that the maize characters reached the optimum under the condition of high fertilizer. The yield of maize is highest when the density is 60000 plants $/ \mathrm{hm}^{2}$ and the amount of fertilizer is $10.71 \mathrm{~kg}$, $3.57 \mathrm{~kg}$ and $8.93 \mathrm{~kg}$ per $667 \mathrm{~m}^{2}$. The experiment of the influence factor of controlled release fertilizer shows that the characters of CRF $V$ and CRF VI are the best. The control time of CRF III, CRF V, CRF VI, and CRF IV compound fertilizer is long, which can increase maize yield. The experiment of the influence factor of fertilizer level shows that the best character of maize is achieved by using the controlled release fertilizer of Agricultural University $450 \mathrm{~kg} / \mathrm{hm}^{2}$ and two-topdressing $600 \mathrm{~kg} / \mathrm{hm}^{2}$. In the process of corn production, the use of A-40 treatment (Volfertile controlled release fertilizer $600 \mathrm{~kg} / \mathrm{hm}^{2}$ ) and the one-time application of base fertilizer can increase the yield of maize. The experiment of the influence factor of fertilization depth and proportion show that the best combination is that seed fertilizer $20 \%$ urea, $40 \%$ diammonium phosphate and potassium sulfate were applied under the surface of $8 \mathrm{~cm}$ and base fertilizer $40 \%$ urea, $60 \%$ diammonium phosphate and potassium sulfate were applied under the surface of $16 \mathrm{~cm}$. It can improve the character and yield of maize at the same time. The experiment of the influence factor of organic manure (chicken manure) shows that the amount of organic fertilizer (chicken manure) $26923 \mathrm{~kg}$ per hectare with fertilizing $35 \mathrm{~kg}$ per plot is the best amount of fertilizer, and the yield of maize increases. The proposed method can comprehensively and accurately analyze the effects of different substrates on the character and yield of maize, which can promote rational fertilization in maize and improve the quality and yield of maize steadily.
\end{abstract}

Keywords: Culture material; Physicochemical property; Maize; Character; Yield; Combined application

\section{INTRODUCTION}

The character and yield of maize are directly related to the development of agricultural production and the capacity of grain production. The use of the culture material greatly increased the grain yield. But with the increase of chemical fertilizer input year by year, the low utilization rate of chemical fertilizer and the decrease of grain output appear (Daya and Pant, 2017; Ashik et al., 2018). In the 19892002 years, the amount of chemical fertilizer increased by $84 \%$, while the grain output increased by only $12 \%$, which shows that the amount of fertilizer application is not consistent with the grain yield increase (Al-zaqri et al., 2017; Anzlovar et al., 2018; Danby et al., 2018; Liu and Liu, 2010;
Liu, 2017). According to the survey, the way of fertilization for farmers is based on split fertilization and one-off fertilization. In recent years, with the development of compound fertilizer technology and the restriction of rural labor force (Wang et al., 2014), the proportion of farmers with one-off basic fertilizer application has gradually increased (Khan, 2018; Atikuzzamman et al., 2018; Abdur Razzak et al., 2018). At present, there are great differences in fertilizer types, fertilizer levels, and application methods in maize production (Ahamed et al., 2018; Khaleel et al., 2018; McClements, 2018). There are widespread problems such as randomness, unscientific method, low utilization rate of fertilizer, large invest and low income of farmers and so on (Salem et al., 2014). Over the years, some scholars 
have done a lot of research on maize fertilization from the aspects of fertilization mode, fertilizer level, and fertilizer type (Ahamed et al., 2017; Girtler, 2017; Kim et al., 2018; Kylili et al., 2018; Mo et al., 2018; Sanchez Camacho and Martinez Morales, 2017). However, there are few reports on the character and yield of maize in terms of the time, proportion, and level of different fertilizers. In order to promote rational fertilization and improve the quality and yield of maize, the effects of different substrates on the character and yield of maize were studied in this paper.

\section{MATERIALS AND METHODS}

The test was carried out in the national Fluvo-aquic soil fertility and fertilizer efficiency monitoring base (Nazli et al., 2016). The base is located in Changping County of Beijing, with the altitude of $20 \mathrm{~m}$, an average annual temperature of 11 degrees, annual rainfall of about $600 \mathrm{~mm}$, drought in winter and rainy in summer, and two crops per year. Soil is Fluvo-aquic soil. The agrochemical properties of plough soil are: Organic matter $1.23 \%, \mathrm{pH}$ value 8.82 , total nitrogen $0.08 \%$, total phosphorus $\mathrm{P}_{2} \mathrm{O}_{5} 0.152 \%$, total potassium $\mathrm{K}_{2} \mathrm{O} 1.75 \%$, available nitrogen $36.07 \mathrm{mg}$ / $\mathrm{kg}$, available phosphorus $\mathrm{P}_{2} \mathrm{O}_{5} 11.16 \mathrm{mg} / \mathrm{kg}$, available potassium $\mathrm{K}_{2} \mathrm{O} 78.61 \mathrm{mg} / \mathrm{kg}$, and slowly available potassium $\mathrm{K}_{2} \mathrm{O} 487.3 \mathrm{mg} / \mathrm{kg}$. The nutrient content of nitrogen and phosphorus is not high, and the soil is alkaline.

In this paper, the test and analysis were carried out in the national Fluvo-aquic soil fertility and fertilizer efficiency monitoring base (Lu and Sun, 2014). In order to make the test results more accurate, the effects of different substrates on the character and yield of maize were analyzed for different test areas (Oechsner, 2015). Excel2003 and SPSS17.0 software is used for data processing and multiple comparisons are carried out by using Duncan's new multiple range test method.

\section{Analysis of effects of different substrates on the character and yield of maize}

The test was carried out in the experimental plot of the base. The area is surrounded by concrete, with the depth of 1 meter and the area of $3 m^{2}(2 \times 1.5 m) .7$ treatments are set up in the experiment. From the angle of the formation of maize character and yield, the effects of different substrates on maize character and yield were analyzed.

\section{Test treatment}

1. CK: No fertilizer.

2. NPK: Each area was applied urea $105 \mathrm{~g}+$ potassium chloride $30 \mathrm{~g}$ (urea $350 \mathrm{~kg} / \mathrm{hm}^{2}+$ calcium superphosphate $500 \mathrm{~kg} / \mathrm{hm}^{2}+$ potassium chloride $100 \mathrm{~kg} / \mathrm{hm}^{2}$ ) per quarter, and the amount of fertilizer determined according to the local fertilization standard.
3. NPK + common-amount organic manure: NPK chemical fertilizer + manure $4.5 \mathrm{~kg}\left(15000 \mathrm{~kg} / \mathrm{hm}^{2}\right)$.

4. NPK + high-amount organic manure: NPK chemical fertilizer + manure $9 \mathrm{~kg}\left(30000 \mathrm{~kg} / \mathrm{hm}^{2}\right)$.

5. NPK + common-amount wheat straw retention: NPK chemical fertilizer + crushed wheat straw $0.67 \mathrm{~kg}\left(2333 \mathrm{~kg} / \mathrm{hm}^{2}\right)$.

6. NPK + high-amount wheat straw retention: NPK chemical fertilizer + crushed wheat straw $1 \mathrm{~kg}(3333 \mathrm{~kg}$ $\left(\mathrm{hm}^{2}\right)$

7. NPK + maize straw retention: NPK chemical fertilizer + crushed maize straw $1 \mathrm{~kg}\left(3333 \mathrm{~kg} / \mathrm{hm}^{2}\right)$

Notes: In addition to applying chemical fertilizer and control treatment, several treatments of organic fertilizer were applied in the above fertilization treatments. The amount of common-amount organic material is based on local fertilization standard. Except control treatment, 6 fertilization treatments were designed and implemented according to the principle of equal nitrogen and phosphorus (Lidia and et al., 2014). Except for the content of nitrogen, phosphorus, and potassium in the organic materials, the insufficient part is replenished with NPK fertilizer, so that the total amount of nitrogen, phosphorus, and potassium is equal to the total amount of fertilizer. The test was repeated 4 times.

\section{Analysis of effects of coupling of fertilization and density on character and yield of maize}

For the phenomenon that the planting density is too thin or too dense and the amount of fertilizer is not reasonable, the effect of the coupling of fertilizer and density on the character and yield of maize is researched in this test (Brienzo et al., 2015), in order to provide reference for high yield and high efficiency cultivation of maize.

The experiment uses two-factor split-plot design, the main area is fertilizer factor with 4 levels, and the secondary area is planting density with 6 levels.

1. High fertilizer. Fertilization of pure N21.42 kg, $\mathrm{P}_{2} \mathrm{O}_{5} 7.14 \mathrm{~kg}, \mathrm{~K}_{2} O 17.86 \mathrm{~kg}$ per $667 \mathrm{~m}^{2}$.

2. Medium fertilizer. Fertilization of pure $N 15.0 \mathrm{~kg}$, $\mathrm{P}_{2} \mathrm{O}_{5} 5.0 \mathrm{~kg}, \mathrm{~K}_{2} \mathrm{O} 12.5 \mathrm{~kg}$ per $667 \mathrm{~m}^{2}$.

3. Low fertilizer. Fertilization of pure $N 10.7 \mathrm{~kg}$, $\mathrm{P}_{2} \mathrm{O}_{5} 3.57 \mathrm{~kg}, \mathrm{~K}_{2} \mathrm{O} 8.93 \mathrm{~kg}$ per $667 \mathrm{~m}^{2}$.

4. No fertilizer.

\section{Test treatment}

Assume the density factor of the secondary area is B, includes 6 levels. B1 B6 are 37500, 45000, 52500, 60000, 67500 , and 75000 plants $/ \mathrm{hm}^{2}$. The total number of treatments is 24 and repeated 3 times. Potash fertilizer and phosphate fertilizer as taken as base fertilizer. The amount of nitrogen fertilizer $20 \%$ is base fertilizer, the case of $20 \%$ 
is seedling fertilizer and the case of $60 \%$ is bract fertilizer. The plant spacing is depended on density. Above 4 rows are set up for protection. After maturity, the middle 2 rows are harvested in each area, and the yield is measured and converted to the yield of the $14 \%$ standard water content. It is repeated 3 times to harvest all. 10 representative ears are taken for test in door. The herbicide measures in different areas are consistent with field management.

\section{Analysis of effects of controlled release fertilizer on character and yield of maize}

The effects of different controlled release fertilizers on the character and yield of maize were researched in this experiment, in order to screen out the best controlled release fertilizer that can increase yield, improve quality, and facilitate application.

\section{Type of fertilizers for test}

1. CRF I and CRF II are coated urea fertilizer produced in Beijing, containing $43 \%$ nitrogen.

2. CRF III is coated compound fertilizer produced in Zhengzhou. The ratio of N, P, and K is 19.4:8.69:9.49.

3. CRF IV is coated compound fertilizer produced by Shandong Agricultural University. The ratio of N, P, and $\mathrm{K}$ is 18:9:9.

4. CRF V and CRF VI are produced in Beijing. The ratio of $\mathrm{N}, \mathrm{P}$, and $\mathrm{K}$ is 13:5:10. The former is not coated, and the latter is coated compound fertilizer.

5. The ratio of $\mathrm{N}, \mathrm{P}$ and $\mathrm{K}$ of the compound fertilizer is 16:16:16, and urea contains pure nitrogen $46 \%$.

Test treatment: 9 treatments are set in the test: The 6 controlled release fertilizers of CRF I, CRF II, CRF III, CRF IV, CRF V, CRF VI and the 3 control groups of CK1, CK 2, and CK 3 .

The controlled-release fertilizer is used as a base fertilizer and applied with seeds at the same depth (Nguyen and et al., 2015). In order to avoid burning seeds, seed and fertilizer are separated $5 \sim 10 \mathrm{~cm}$. CK1, CK 2, and are the double controls of CRF I and CRF II, and CK 3, is the control of the CRF III, CRF IV, CRF V, and CRF VI. Specific amount of fertilizer application is shown in Table 1. Repeat 3 times. The planting density is 60 thousand plants $/ \mathrm{hm}^{2}$.

\section{Analysis of effects of fertilization level on the character and yield of maize}

In this test, the effects of fertilizer levels of different culture materials with similar cultivation conditions on the character and yield of maize were studied (Urrea-López et al., 2014), in order to promote scientific and rational fertilization of maize, improve the utilization efficiency of fertilizer, and provide theoretical guidance for improving maize yield of unit area. The test field has well irrigation
Table 1: Treatment of fertilizer application

\begin{tabular}{lc}
\hline Handle & Application amount \\
\hline Control I & 900 \\
Control II & 900 \\
CK1 & 900 urea (base fertilizer) \\
CK2 & 450 urea (base fertilizer) \\
& +450 urea (big chasing) \\
Control III & 1500 \\
Contro IV & 1500 \\
Control V & 2070 \\
Control VI & 2070 \\
CK3 & 750 compound fertilizer (base fertilizer) \\
& +330 urea (big chasing) \\
\hline
\end{tabular}

Table 2: Experimental treatment

\begin{tabular}{llc}
\hline $\begin{array}{l}\text { Processing } \\
\text { number }\end{array}$ & $\begin{array}{l}\text { Type of } \\
\text { fertilization }\end{array}$ & $\begin{array}{c}\text { Amount of } \\
\text { fertilizer }\left(\mathbf{k g} / \mathbf{h m}^{2}\right)\end{array}$ \\
\hline A-30 & FertilizerA & 450 \\
A-40 & FertilizerA & 600 \\
A-50 & FertilizerA & 750 \\
B-30 & FertilizerB & 450 \\
B-40 & FertilizerB & 600 \\
B-50 & FertilizerB & 750 \\
C-30 & FertilizerC & 450 \\
C-40 & FertilizerC & 600 \\
C-50 & FertilizerC & 750 \\
CK1-30 & Primary fertilization & 450 \\
CK1-35 & Primary fertilization & 525 \\
CK1-40 & Primary fertilization & 600 \\
CK2-30 & Two manuring & 450 \\
CK2-35 & Two manuring & 525 \\
CK2-40 & Two manuring & 600 \\
\hline
\end{tabular}

Fertilizer A is the controlled release fertilizer of wolf, $\mathrm{N}$ and $\mathrm{P}_{2} \mathrm{O}_{5}$ were $26 \%$, $10 \%$ and $12 \%$,respectively; Fertilizer B is Liaozhongjing compound fertilizer, $\mathrm{N}, \mathrm{P}_{2} \mathrm{O}_{5}$ and $\mathrm{K}_{2} \mathrm{O}$ were $26 \%, 10 \%$ and $12 \%$,respectively; Fertilizer $\mathrm{C}$ is the controlled release fertilizer of Agricultural University, $\mathrm{N}, \mathrm{P}_{2} \mathrm{O}_{5}, \mathrm{~K}_{2} \mathrm{O}$ and were $26 \%, 6 \%$ and $8 \%$, respectively; Two amine phosphoric acid containing $\mathrm{N} 18 \%, \mathrm{P}_{2} \mathrm{O}_{5}$ containing $46 \%$; Urea containing $46 \%$.A, B and $\mathrm{C}$ were treated with bottom fertilizer once;CK1 phosphoric acid two amine $225 \mathrm{~kg} / \mathrm{hm}^{2}$ is used as base fertilizer once and urea as top dressing at a large bell stage;CK2 phosphoric acid two amine $225 \mathrm{~kg} / \mathrm{hm}^{2}$ was used as base fertilizer once, urea as top dressing at jointing stage $1 / 2$ and $1 / 2$ at big bell stage

condition, and 15 treatments are set up, which is shown in Table 2.

The planting density of the tested maize was 67.5 thousand plants $/ \mathrm{hm} 2$. The length of the row of the test plot is $5 \mathrm{~m}$. The area has 6 rows. The test repeats 3 times and has randomized block arrangement. 4 rows of protection rows are set in the surrounding area of the test area. 10 ears were selected by using the average ear method for each treatment. The ear length, ear diameter, bald tip length, row number, row grain number, 100 grain quality and yield were determined. The steps of taking ear by average ear method are: The average fresh weight (FW) is obtained by of the ear weight of each plot divided by the number of ears. The fresh weight of each typical ear is selected close 
to or equal to FW. 10 representative ears are marked for seed test.

\section{Analysis of effects of depth and proportion of fertilization on character and yield of maize}

The test treatment was divided into two parts: fertilization depth $A$ and fertilization proportion $B$. The fertilization depth A sets 3 levels. A1 fertilization depth is 0,8 , and $16 \mathrm{~cm}$, A2 fertilization depth is 0,10 , and $16 \mathrm{~cm}$, and A3 fertilization depth is 0,12 , and $16 \mathrm{~cm}$.

The fertilization proportion B sets 3 levels.

1. B1: Fertilizer with sowing is $10 \%$ urea, $30 \%$ diammonium phosphate, and potassium sulfate. Base fertilizer is $50 \%$ urea, 30\% diammonium phosphate, and potassium sulfate.

2. B2: Fertilizer with sowing is 20\% urea, $30 \%$ diammonium phosphate, and potassium sulfate. Base fertilizer is $50 \%$ urea, $60 \%$ diammonium phosphate, and potassium sulfate.

3. B3: Fertilizer with sowing is 30\% urea, 50\% diammonium phosphate, and potassium sulfate. Base fertilizer is $30 \%$ urea, $50 \%$ diammonium phosphate, and potassium sulfate.

Each factor sets 3 levels, and 9 treatments are formed through orthogonal combination. The treatments from 1 to 9 are A1B1, A1B2, A1B3, A2B1, A2B2, A2B2, A2B3, $\mathrm{A} 3 \mathrm{~B} 1, \mathrm{~A} 3 \mathrm{~B} 2$, and $\mathrm{A} 3 \mathrm{~B} 3$. In addition, fertilizer is divided into three layers of seed fertilizer, fertilizer with sowing, and base fertilizer. 4 treatments are selected to test.

1. Treatment 10: Fertilization depth is 3, 8, and $16 \mathrm{~cm}$. Seed fertilizer is $10 \%$ diammonium phosphate, and potassium sulfate, fertilizer with sowing is $10 \%$ urea, $20 \%$ diammonium phosphate, and potassium sulfate, and base fertilizer is $50 \%$ urea, $70 \%$ diammonium phosphate, and potassium sulfate.

2. Treatment 11: Fertilization depth is 3,10, and $16 \mathrm{~cm}$. Seed fertilizer is $10 \%$ diammonium phosphate and potassium sulfate, fertilizer with sowing is $10 \%$ urea, $20 \%$ diammonium phosphate, and potassium sulfate, and base fertilizer is $50 \%$ urea, $70 \%$ diammonium phosphate, and potassium sulfate.

3. Treatment 12: Fertilization depth is 3,12, and $16 \mathrm{~cm}$. Seed fertilizer is $10 \%$ diammonium phosphate and potassium sulfate, fertilizer with sowing is $10 \%$ urea, $20 \%$ diammonium phosphate, and potassium sulfate, and base fertilizer is $50 \%$ urea, $70 \%$ diammonium phosphate, and potassium sulfate.

4. Treatment 13: Fertilization depth is 3 and $12 \mathrm{~cm}$. Seed fertilizer is $10 \%$ diammonium phosphate and potassium sulfate, and base fertilizer is 60\% urea, $90 \%$ diammonium phosphate, and potassium sulfate.

5. Treatment 14 is a control group. Fertilization depth is 0 and $12 \mathrm{~cm}$. Base fertilizer is $60 \%$ urea, $100 \%$ diammonium phosphate, and potassium sulfate. The control is applied to the whole fertilizer as the base fertilizer (Zhang et al., 2014). There is a total of 14 treatments, and 6 ridges per treatment. Ridge spacing is $1.1 \mathrm{~m}$, the length of the row is $10 \mathrm{~m}$, the area of each plot is $66 \mathrm{~m}^{2}$, and the test area is $924 \mathrm{~m}^{2}$.

In each treatment, $40 \%$ nitrogen fertilizer is retained for manuring before jointing (Pavlović et al., 2015). Before seeding, the fertilizer is packaged quantitatively with mechanical fertilizer and artificial seeding. When the maize has 2 3 leaves, deep loosening is carried out. The ploughing is carried out before jointing and 40\% urea is applied. Artificial weeding is carried out during the growth period. The pure amount of fertilizer per hectare is $\mathrm{N}$ $67.5 \mathrm{~kg}, \mathrm{P}_{2} \mathrm{O}_{5} 45.0 \mathrm{~kg}$, and $\mathrm{K}_{2} \mathrm{O} 26.2 \mathrm{~kg}$.

Analysis of effects of different amounts of organic manure (chicken manure) on character and yield of maize The effects of organic fertilizer (chicken manure) on the character and yield of maize are analyzed. Organic manure is denoted as T. 7 treatments are carried out. T1: No fertilizer; T2: 15kg; T3: 20kg; T4: 25kg; T5: 30kg; T6: 35kg; T7: 40kg.

The area of the test area is $13 \mathrm{~m}^{2}$. Repeat 3 times. There are 4 rows, the length of the row is $5 \mathrm{~cm}$, the row spacing is $65 \mathrm{~cm}$, and the plat spacing is $30 \mathrm{~cm}$. Field investigation is carried out according to the experimental scheme in the whole process of maize growth (Shin and Jeong, 2014). Each plot is measured individually during harvest. All treatments adopt uniform cultivation management and control measures from grass damage.

\section{EFFECTS OF PHYSICOCHEMICAL PROPERTIES OF DIFFERENT SUBSTRATES ON CHARACTER AND YIELD OF MAIZE}

\section{Effects of combined application of different substrates on character and yield of maize}

The test results of effects of nitrogen, phosphorus and potassium fertilizer combined with different organic materials on the character and yield of maize are shown in Table 3 and Table 4.

$$
L S D_{0.06}=2887.4596, L S D_{0.01}=3955.3100
$$

\section{Effects of fertilization and density coupling of different} substrates on characters and yield of maize

The test results of effects of fertilization and density coupling of different substrates on characters and yield of maize are shown in Table 2 and Table 5. Table 6 shows the difference significance analysis of component factor of maize yield. 
Ren, et al.

Table 3: Effects of different substrates on maize growth and development

\begin{tabular}{|c|c|c|c|c|c|c|c|}
\hline Handle & 1 & 2 & 3 & 4 & 5 & 6 & 7 \\
\hline Ear length $(\mathrm{cm})$ & 10.9 & 15.1 & 15.6 & 15.6 & 14.6 & 14.7 & 15 \\
\hline More than control\% & - & 38.5 & 43.1 & 43.1 & 33.9 & 34.9 & 37.6 \\
\hline \multicolumn{8}{|l|}{ Difference saliency } \\
\hline 0.05 & $b$ & a & a & a & a & a & a \\
\hline 0.01 & B & A & A & A & A & A & A \\
\hline Panicle girth $(\mathrm{cm})$ & 12.1 & 13.9 & 14.4 & 14.6 & 14.1 & 14.1 & 14.1 \\
\hline More than control\% & - & 14.9 & 19 & 20.7 & 16.5 & 16.5 & 16.5 \\
\hline \multicolumn{8}{|l|}{ Difference saliency } \\
\hline 0.05 & $\mathrm{~b}$ & a & a & a & a & a & a \\
\hline 0.01 & B & A & A & A & A & A & A \\
\hline Number of spikes & 247 & 413 & 435 & 450 & 398 & 420 & 416 \\
\hline More than control\% & - & 67.2 & 76.1 & 82.2 & 61.1 & 70 & 68.4 \\
\hline \multicolumn{8}{|l|}{ Difference saliency } \\
\hline 0.05 & $b$ & a & a & a & a & a & a \\
\hline 0.01 & B & A & $A$ & A & A & A & A \\
\hline 100 grain weight(g) & 19.8 & 23.9 & 25.9 & 26.6 & 25 & 24.9 & 24.5 \\
\hline More than control\% & - & 20.7 & 30.8 & 34.3 & 26.3 & 25.8 & 23.7 \\
\hline \multicolumn{8}{|l|}{ Difference saliency } \\
\hline 0.05 & c & $b$ & $a b$ & a & $a b$ & $a b$ & $b$ \\
\hline 0.01 & C & B & $A B$ & A & $\mathrm{AB}$ & $A B$ & B \\
\hline
\end{tabular}

The LSD method was used to determine the difference significance.

Table 4: Effects of different substrates on Maize Yield $\left(\mathrm{kg} / \mathrm{hm}^{2}\right)$

\begin{tabular}{|c|c|c|c|c|c|c|c|}
\hline \multirow[t]{2}{*}{ Handle } & \multirow[t]{2}{*}{2012} & \multirow[t]{2}{*}{2013} & \multirow[t]{2}{*}{2014} & \multirow[t]{2}{*}{$\mathbf{x}$} & \multirow{2}{*}{$\begin{array}{l}\text { Increase production } \\
\text { than control(\%) }\end{array}$} & \multicolumn{2}{|c|}{ Difference saliency } \\
\hline & & & & & & 0.05 & 0.01 \\
\hline NPK+ high quantity organic fertilizer & 16105.00 & 15570.84 & 17704.17 & 16460.00 & 147.6 & a & A \\
\hline NPK+ constant organic manure & 15802.50 & 13920.83 & 16508.34 & 15410.56 & 131.8 & $a b$ & A \\
\hline NPK+ high wheat straw & 15888.33 & 12245.83 & 13471.67 & 13868.55 & 108.6 & $a b$ & $A$ \\
\hline NPK+ constant wheat straw & 15200.00 & 11345.83 & 13945.84 & 13497.22 & 103.0 & b & $A$ \\
\hline NPK & 13579.17 & 10966.67 & 13812.5 & 12786.11 & 92.3 & $\mathrm{~b}$ & A \\
\hline NPK+ corn stalk & 11678.63 & 11408.34 & 14933.34 & 12673.44 & 90.6 & c & B \\
\hline CK & 8909.50 & 4979.17 & 6058.33 & 6648.89 & - & & \\
\hline
\end{tabular}

Effects of controlled release of different substrates on characters and yield of maize

The test results of effects of the controlled release of different substrates on characters and yield of maize are shown in Table 7 and Table 8.

\section{Effects of fertilization level of different substrates on} characters and yield of maize

The test results of effects of fertilization level of different substrates on characters and yield of maize are shown in Table 9 and Table 10.

Effects of fertilization depth and proportion of different substrates on characters and yield of maize

The test results of effects of fertilization depth and proportion of different substrates on characters and yield of maize are shown in Table 11.
Effects of different amounts of organic manure (chicken manure) on character and yield of maize

The test results of effects of different amounts of organic manure (chicken manure) on character and yield of maize are shown in Table 12 and Table 13.

\section{DISCUSSIONS}

Discussions of effects of combined application of different substrates on character and yield of maize

NPK fertilizer combined with different organic materials has great effects on ear length, ear circumference, and grain number per ear (Robson et al, 2015). The difference of comparison of the 6 treatments of NPK, NPK+ organic fertilizer (common-amount, high-amount), NPK+ wheat straw retention (common-amount, high-amount), and $\mathrm{NPK}+$ corn straw retention and the control group reach a very significant level. The effects of the treatments of 
$\mathrm{NPK}+$ organic fertilizer (common-amount, high-amount) are best. But there is no significant difference between 6 fertilization treatments.

6 fertilization treatments had obvious effects on increasing grain number of maizes. The grain number of the NPK+ high organic fertilizer treatment is highest, followed by $\mathrm{NPK}+$ constant organic fertilizer treatment. The other treatments are close to NPK.

The 100-grain weight ratio of the 6 treatments increases significantly compared with the control group and the difference reaches a very significant level. The treatment of $\mathrm{NPK}+$ high organic fertilizer has the best effect, and the difference reaches a very significant level compared with that of NPK treatment and NPK+ maize straw retention.

From Table 4, it can be seen that, NPK fertilizer combined with organic materials can play a positive role in improving

Table 5: Effects of fertilization and density coupling on yield of maize with different substrates

\begin{tabular}{lccc}
\hline Fertilizer level & $\begin{array}{c}\text { Density } \\
\text { (plant } / \mathrm{hm}^{2} \text { ) }\end{array}$ & yield & $\begin{array}{c}\text { Production and } \\
\text { investment ratio }\end{array}$ \\
\hline High fertilizer & 67500 & $661.3 \mathrm{aA}$ & 4.42 \\
& 60000 & $610.8 \mathrm{abAB}$ & 4.08 \\
& 52500 & $580.4 \mathrm{bcAB}$ & 3.88 \\
& 75000 & $566.4 \mathrm{bcAB}$ & 3.79 \\
& 45000 & $565.4 \mathrm{bcAB}$ & 3.78 \\
Medium fertilizer & 37500 & $524.1 \mathrm{cB}$ & 3.50 \\
& 60000 & $589.2 \mathrm{aA}$ & 5.63 \\
& 52500 & $569.9 \mathrm{aAB}$ & 5.44 \\
& 67500 & $514.0 \mathrm{bBC}$ & 4.91 \\
& 45000 & $506.4 \mathrm{bBC}$ & 4.84 \\
& 75000 & $497.8 \mathrm{bcC}$ & 4.76 \\
& 37500 & $455.6 \mathrm{cC}$ & 4.35 \\
& 60000 & $571.4 \mathrm{aA}$ & 7.65 \\
& 52500 & $531.4 \mathrm{abAB}$ & 7.11 \\
& 45000 & $494.0 \mathrm{bcABC}$ & 6.61 \\
& 37500 & $465.8 \mathrm{bcdBC}$ & 6.23 \\
& 67500 & $457.5 \mathrm{cdBC}$ & 6.12 \\
& 75000 & $404.5 \mathrm{cdBC}$ & 5.41 \\
\hline & 45000 & $465.6 \mathrm{aA}$ & \\
\hline & 52500 & $433.5 \mathrm{abAB}$ & \\
& 37500 & $412.9 \mathrm{abcAB}$ & \\
& 60000 & $382.4 \mathrm{bcAB}$ & \\
67500 & $345.9 \mathrm{cB}$ & \\
& 75000 & $335.4 \mathrm{cB}$ & \\
\hline
\end{tabular}

Corn price is calculated at 2.2 yuan $/ \mathrm{kg}$, and fertilizer cost is only included in the cost maize yield (Huang et al., 2014). Compared with the control, the difference reaches a very significant level. The productions of 4 treatments of NPK + organic fertilizer (common-amount, high-amount) and NPK + wheat straw retention (commonamount, high-amount) are more than double of the control.

\section{Discussions of effects of fertilization and density coupling of different substrates on characters and yield of maize}

From Table 14, it can be seen that, the effect of fertilizer factors on the plant character and ear character of maize has no significant difference on 1000-grain weight, and the influence on the other character reaches a very significant level. In the treatment of 4 fertilizers, the high fertilizer treatment is the highest in other indexes except that the height of the plant and grain number per row is second and the 1000-grain weight is the third. The effects of density on plant character and ear character are significant (Khila et al., 2016). With the increase of density, stem diameter, ear length, ear diameter, row number per row, row grain number, and 1000-grain weight are decreased. For B1 (37500 plants $\left./ \mathrm{hm}^{2}\right)$, these indexes are the highest. With the increase of density, plant height, ear position and barren tip are increasing. For B6 (75000 plants $\left./ \mathrm{hm}^{2}\right)$, these indexes are the highest.

From Table 6 and Table 5, it can be seen that, the coupling effect of fertilizer and density has significant difference in the interaction effect of barren tip, 1000-grain weight, and yield. There is a significant difference in yield between different levels of fertilizer.

1. Under high fertilizer condition, the yield of 67500 plants $/ \mathrm{hm}^{2}$ is the highest and the one of 67500 plants $/ \mathrm{hm}^{2}$ is the second, and there is no significant difference between 2 densities.

2. Under medium fertilizer condition, the yield of 60000 plants $/ \mathrm{hm}^{2}$ is the highest and the one of 52500 plants $/ \mathrm{hm}^{2}$ is the second, and there is no significant difference between 2 densities.

3. Under low fertilizer condition, the yield of 60000 plants $/ \mathrm{hm}^{2}$ is the highest and the one of 52500 plants $/ \mathrm{hm}^{2}$ is the second, and there is no significant difference between 2 densities.

4. Under no fertilizer condition, the yield of 45000 plants $/ \mathrm{hm}^{2}$ is the highest and the ones of 52500 and 37500 plants $/ \mathrm{hm}^{2}$ is followed, and there is no significant difference between 3 densities.

Table 6: Difference significance analysis of maize yield components

\begin{tabular}{|c|c|c|c|c|c|c|c|}
\hline Source of variation & Ear length & Spike width & Ear row number & Grain number & Alopecia apex & 1000 grain weight & Yield \\
\hline$A$ & $* *$ & $*$ & & & ** & * & ** \\
\hline B & ** & ** & * & ** & ** & ** & ** \\
\hline$A \times B$ & & & & & ** & * & ** \\
\hline
\end{tabular}


Ren, et al.

Table 7: Effects of controlled release of different substrates on maize characters

\begin{tabular}{|c|c|c|c|c|c|c|c|c|c|c|c|c|c|c|c|c|}
\hline \multirow[t]{2}{*}{ Handle } & \multirow[t]{2}{*}{$\begin{array}{c}\text { Ear } \\
\text { length(cm) }\end{array}$} & \multicolumn{3}{|c|}{$\begin{array}{c}\text { Increase or } \\
\text { decrease(\%) }\end{array}$} & \multirow{2}{*}{$\begin{array}{c}\begin{array}{c}\text { spike } \\
\text { width(cm) }\end{array} \\
4.86\end{array}$} & \multicolumn{3}{|c|}{$\begin{array}{c}\text { Increase or } \\
\text { decrease(\%) }\end{array}$} & \multirow[t]{2}{*}{$\begin{array}{c}\text { Seed } \\
\text { yield(\%) }\end{array}$} & \multicolumn{3}{|c|}{$\begin{array}{c}\text { Increase or } \\
\text { decrease(\%) }\end{array}$} & \multirow[t]{2}{*}{$\begin{array}{l}1000 \text { grain } \\
\text { weight(g) }\end{array}$} & \multicolumn{3}{|c|}{$\begin{array}{c}\text { Increase or } \\
\text { decrease(\%) }\end{array}$} \\
\hline & & $\mathrm{CK}_{1}$ & $\mathrm{CK}_{2}$ & $\mathrm{CK}_{3}$ & & $\mathrm{CK}_{1}$ & $\mathrm{CK}_{2}$ & $\mathrm{CK}_{3}$ & & $\mathrm{CK}_{1}$ & $\mathrm{CK}_{2}$ & $\mathrm{CK}_{3}$ & & $\mathrm{CK}_{1}$ & $\mathrm{CK}_{2}$ & $\mathrm{CK}_{3}$ \\
\hline Control I & 18.5 & 1.1 & -2.1 & & 4.86 & -4.5 & -5.3 & & 86.8 & -0.9 & -0.6 & & 262.1 & -6.0 & -15.4 & \\
\hline Control II & 18.7 & 2.2 & -1.1 & & 4.94 & -2.9 & -3.7 & & 86.9 & -0.8 & -0.5 & & 280.4 & 0.6 & -9.5 & \\
\hline $\mathrm{CK}_{1}$ & 18.3 & 0.0 & & & 5.09 & 0.0 & & & 87.6 & 0.0 & & & 278.8 & 0.0 & & \\
\hline $\mathrm{CK}_{2}$ & 18.9 & & 0.0 & & 5.13 & & 0.0 & & 87.3 & & 0.0 & & 309.7 & & 0.0 & \\
\hline Control III & 19.7 & & & 1.0 & 5.10 & & & -0.2 & 86.9 & & & -0.1 & 309.7 & & & 2.6 \\
\hline Control IV & 19.3 & & & -1.0 & 5.18 & & & 1.4 & 85.8 & & & -1.4 & 312.5 & & & 3.5 \\
\hline Control V & 21.2 & & & 8.7 & 5.19 & & & 1.6 & 87.0 & & & 0.0 & 329.7 & & & 9.2 \\
\hline Control VI & 17.6 & & & 0.5 & 5.17 & & & 1.2 & 87.7 & & & 0.8 & 322.3 & & & 6.8 \\
\hline $\mathrm{CK}_{3}$ & 19.5 & & & 0.0 & 5.11 & & & 0.0 & 87.0 & & & 0.0 & 301.9 & & & 0.0 \\
\hline
\end{tabular}

Table 8: Effects of controlled release of different substrates on maize yield

\begin{tabular}{|c|c|c|c|c|}
\hline Handle & Average yield(kg/hm²) & And $\mathrm{CK}_{1} \pm(\%)$ & And $\mathrm{CK}_{2} \pm(\%)$ & And $\mathrm{CK}_{3} \pm(\%)$ \\
\hline Control I & 7683.15 & -9.2 & -15.8 & \\
\hline Control II & 8211.75 & -2.9 & -10.0 & \\
\hline $\mathrm{CK}_{1}$ & 8457.15 & 0.0 & & \\
\hline $\mathrm{CK}_{2}$ & 9121.05 & & 0.0 & \\
\hline Control III & 9942.15 & & & 0.5 \\
\hline Control IV & 9923.85 & & & 0.3 \\
\hline Control V & 10696.20 & & & 8.1 \\
\hline Control VI & 9930.90 & & & 0.4 \\
\hline $\mathrm{CK}_{3}$ & 9893.10 & & & 0.0 \\
\hline
\end{tabular}

Table 9: Effect of fertilization level of different substrates on maize characters

\begin{tabular}{|c|c|c|c|c|c|c|}
\hline Handle & Ear length (cm) & Spike width (cm) & Alopecia apex $(\mathrm{cm})$ & 100 grain weight(g) & Ear row number & Grain number \\
\hline$A-30$ & 18.5Aab & 5.17Aa & $0.3 A a b$ & $34.2 A a$ & 15.6Aab & $38.7 \mathrm{Bc}$ \\
\hline$A-40$ & 19.1Aa & $5.20 A a$ & $1.0 \mathrm{Aa}$ & $34.4 \mathrm{Aa}$ & 16.4Aab & 40.7ABab \\
\hline$A-50$ & 19.2Aa & $5.20 \mathrm{Aa}$ & $0.7 \mathrm{Aa}$ & $34.2 \mathrm{Aa}$ & $15.2 \mathrm{Aa}$ & 41.7ABab \\
\hline B-30 & 18.7Aab & $5.18 \mathrm{Aa}$ & $1.3 \mathrm{Aa}$ & $35.4 \mathrm{Aa}$ & 15.5Aab & 41.0ABab \\
\hline B-40 & 18.8Aab & 5.33Aa & $0.7 A a b$ & $34.4 \mathrm{Aa}$ & 15.8Aab & 42.0Aab \\
\hline$B-50$ & 18.8Aab & $5.16 \mathrm{Aa}$ & $1.3 \mathrm{Aa}$ & $34.6 \mathrm{Aa}$ & 15.3Aab & 41.0ABab \\
\hline C-30 & $19.2 \mathrm{Aa}$ & $5.22 \mathrm{Aa}$ & $0.0 A b$ & 34.7Aa & 15.7Aab & 41.3ABab \\
\hline C-40 & 18.9Aab & $5.24 \mathrm{Aa}$ & $1.0 \mathrm{Aa}$ & $34.8 A a$ & 15.7Aab & 40.3ABab \\
\hline$C-50$ & 18.5Aab & $5.15 \mathrm{Aa}$ & $1.0 \mathrm{Aa}$ & $34.3 \mathrm{Aa}$ & $15.2 A b$ & $40.1 \mathrm{ABab}$ \\
\hline $\mathrm{CK}_{1}-30$ & 18.8Aab & $5.17 \mathrm{Aa}$ & 1.3Aa & 35.3Aa & $15.1 \mathrm{Ab}$ & 41.8ABab \\
\hline $\mathrm{CK}_{1}-35$ & 18.8Aab & $5.21 \mathrm{Aa}$ & $1.0 \mathrm{Aa}$ & 35.3Aa & $16.6 \mathrm{Aa}$ & 40.9ABab \\
\hline $\mathrm{CK}_{1}-40$ & 18.2Aab & 5.17Aa & $1.3 \mathrm{Aa}$ & $35.0 \mathrm{Aa}$ & 16.2Aa & 40.9ABab \\
\hline $\mathrm{CK}_{2}-30$ & 18.2Aab & $5.17 A a$ & $0.7 A a b$ & $34.2 A a$ & 15.5Aab & 40.5ABab \\
\hline $\mathrm{CK}_{2}-35$ & $17.9 A b$ & $5.08 \mathrm{Aa}$ & $1.0 \mathrm{Aa}$ & $34.9 A a$ & $14.9 \mathrm{Ab}$ & 40.0ABab \\
\hline $\mathrm{CK}_{2}-40$ & 19.0Aa & $5.25 \mathrm{Aa}$ & $0.0 A b$ & 35.3Aa & $16.5 \mathrm{Aa}$ & 43.0ABab \\
\hline
\end{tabular}

5. From the production to investment ratio, the production to investment ratio decreases with the increase of fertilizer amount. The amount of fertilizer with the best economic benefit is low fertilizer, the investment per $667 \mathrm{~m}^{2}$ fertilizer is 164.4 yuan, and the average production to investment ratio of 6 densities is 6.52. The next is the medium fertilizer, the investment per $667 \mathrm{~m}^{2}$ fertilizer is 230.3 yuan, and the average production to investment ratio of the 6 densities is 4.99. The worst is high fertilizer, the investment per
$667 \mathrm{~m}^{2}$ fertilizer is 329 yuan, and the average production to investment ratio of 6 densities is 3.91 .

Discussions of effects of controlled release of different substrates on characters and yield of maize

From Table 7, it can be seen that, CRF V and CRF VI have the best characters and CRF III and CRF IV are followed. The yield increasing effect of these two fertilizers is mainly on 1000-grain weight. The character of CRF IV is in general and close to the control (Barakat et al, 2014). 
From Table 8, it can be seen that, different controlled release fertilizers have different effects on maize yield. The yield of CRF I is 5.5\% and 2.4\% higher than that of $C K_{1}$ and $C K_{2}$, respectively. The yield of CRF II is $7.2 \%$ and $10.4 \%$ lower than that of and $C K_{1}, C K_{2}$ respectively. The results show that the CRF II could not increase the yield of maize. The yields of CRF III, CRF IV, CRF V and CRF VI are 9.9\%, 5.1\%, $13.5 \%$, and $7.2 \%$ higher than that of $C K_{3}$, respectively. It shows that these 4 controlled release compound fertilizers have significant effect on the increase of maize yield. The yields of CRF I and CRF II are not better than those of $C K_{1}$ and $C K_{2}$. The yield of CRF I is $9.2 \%$ and $15.8 \%$ lower than that of $C K_{1}$ and $C K_{2}$, respectively. The yield of CRF II is $2.9 \%$ and $10.0 \%$ lower than that of $C K_{1}$ and $C K_{2}$, respectively. It can be clearly seen that these two controlled release fertilizers can not only increase the yield of maize, but also greatly reduce the yield. The yields of CRF III, CRF IV, CRF V and CRF VI are $0.5 \%, 0.3 \%, 8.1 \%$, and $0.4 \%$ higher than that of $C K_{3}$, respectively. The increase

Table 10: Effect of fertilization level on yield of maize with different substrates

\begin{tabular}{lc}
\hline Handle & Yield $\left(\mathbf{k g} / \mathbf{h m}^{2}\right)$ \\
\hline A-30 & $11864.3 \mathrm{cdBC}$ \\
$\mathrm{A}-40$ & $13546.0 \mathrm{abA}$ \\
$\mathrm{A}-50$ & $12212.3 \mathrm{cB}$ \\
$\mathrm{B}-30$ & $11657.5 \mathrm{cdBC}$ \\
$\mathrm{B}-40$ & $12010.5 \mathrm{cdBC}$ \\
$\mathrm{B}-50$ & $11342.4 \mathrm{dC}$ \\
$\mathrm{C}-30$ & $11760.3 \mathrm{cdBC}$ \\
$\mathrm{C}-40$ & $12370.5 \mathrm{cB}$ \\
$\mathrm{C}-50$ & $11816.6 \mathrm{cdBC}$ \\
$\mathrm{CK}_{1}-30$ & $11313.2 \mathrm{dC}$ \\
$\mathrm{CK}_{1}-35$ & $12328.5 \mathrm{cB}$ \\
$\mathrm{CK}_{1}-40$ & $11821.9 \mathrm{csBC}$ \\
$\mathrm{CK}_{2}-30$ & $11423.7 \mathrm{dC}$ \\
$\mathrm{CK}_{2}-35$ & $11998.0 \mathrm{cdBC}$ \\
$\mathrm{CK}_{2}-40$ & $13925.1 \mathrm{aA}$ \\
\hline
\end{tabular}

production effect of CRF I is the best. In general, the ratio of nitrogen, phosphorus and potassium of the 4 controlled release fertilizers of CRF III, CRF IV, CRF V, and CRF $\mathrm{VI}$, is reasonable and the control time is long. As a oneoff application of base fertilizer, it can meet the demand of fertilizer nutrition for maize growth and development (Shen et al., 2014). Therefore, compared with the traditional fertilization method, it saves time and effort, and can effectively increase the yield of maize.

\section{Discussions of effects of fertilization level of different substrates on characters and yield of maize}

From Table 9, it can be seen that, the ear length obtained with the treatments of the Volfertile controlled release fertilizer 600 and $750 \mathrm{~kg} / \mathrm{hm}^{2}$, and controlled release fertilizer of Agricultural University $450 \mathrm{~kg} / \mathrm{hm}^{2}$, and twotopdressing $600 \mathrm{~kg} / \mathrm{hm}^{2}$ are higher than the treatment of two-topdressing $525 \mathrm{~kg} / \mathrm{hm}^{2}$. The largest of the barren tip is the Liaozhongiing compound fertilizer 450 and $750 \mathrm{~kg} / \mathrm{hm}^{2}$ and one topdressing 450 and $600 \mathrm{~kg} / \mathrm{hm}^{2}$. The controlled release fertilizer of Agricultural University $450 \mathrm{~kg} / \mathrm{hm}^{2}$ and two-topdressing $600 \mathrm{~kg} / \mathrm{hm}^{2}$ show the best performance, without barren tip. The ear row number obtained with the treatments of Volfertile controlled release fertilizer $600 \mathrm{~kg} / \mathrm{hm}^{2}$, one topdressing 525 and $600 \mathrm{~kg} / \mathrm{hm}^{2}$, and two-topdressing $600 \mathrm{~kg} / \mathrm{hm}^{2}$ is larger than the treatments of controlled release fertilizer of Agricultural University $750 \mathrm{~kg} / \mathrm{hm}^{2}$, one topdressing $450 \mathrm{~kg} / \mathrm{hm}^{2}$, and twotopdressing $525 \mathrm{~kg} / \mathrm{hm}^{2}$. There is no significant difference between the other treatments. For grain number per row, the two-topdressing $600 \mathrm{~kg} / \mathrm{hm}^{2}$ treatment is the largest, with 43 grains, and 4.3 grains per row more than the Volfertile controlled release fertilizer $450 \mathrm{~kg} / \mathrm{hm}^{2}$ with the minimum number. The treatments of two-topdressing $600 \mathrm{~kg} / \mathrm{hm}^{2}$, Liaozhongjing compound fertilizer $600 \mathrm{~kg} /$ $\mathrm{hm}^{2}$ and one topdressing $450 \mathrm{~kg} / \mathrm{hm}^{2}$ are significantly

Table 11: Effect of fertilization depth and proportion on yield and quality of Maize

\begin{tabular}{|c|c|c|c|c|c|c|c|c|c|c|}
\hline Handle & $\begin{array}{c}\text { Plant } \\
\text { height(cm) }\end{array}$ & $\begin{array}{c}\text { Ear } \\
\text { position }(\mathrm{cm})\end{array}$ & $\begin{array}{l}\text { Ear length } \\
\quad(\mathrm{cm})\end{array}$ & $\begin{array}{c}\text { Spike } \\
\text { width }(\mathrm{cm})\end{array}$ & $\begin{array}{l}\text { Alopecia } \\
\text { apex }(\mathrm{cm})\end{array}$ & $\begin{array}{l}\text { Ear row } \\
\text { number }\end{array}$ & $\begin{array}{c}\text { Grain } \\
\text { number }\end{array}$ & $\begin{array}{l}100 \text { grain } \\
\text { weight(g) }\end{array}$ & $\begin{array}{c}\text { Number of } \\
\text { plants } \\
\text { (individual } / \mathrm{m}^{2} \text { ) }\end{array}$ & $\begin{array}{c}\text { Yield } \\
\left(\mathrm{kg} / \mathrm{hm}^{2}\right)\end{array}$ \\
\hline 1 & 263 & 90 & 16.9 & 4.8 & 0.9 & 16 & 27 & 31.8 & 8.4 & 11856 \\
\hline 2 & 273 & 95 & 15.4 & 4.4 & 1.0 & 16 & 25 & 32.5 & 8.8 & 12081 \\
\hline 3 & 262 & 88 & 17.3 & 4.7 & 0.7 & 16 & 31 & 33.1 & 8.5 & 13057 \\
\hline 4 & 247 & 90 & 17.1 & 4.7 & 0.7 & 16 & 27 & 33.1 & 8.6 & 12156 \\
\hline 5 & 246 & 90 & 16.8 & 4.8 & 0.7 & 16 & 29 & 33.1 & 8.5 & 13132 \\
\hline 6 & 255 & 85 & 15.8 & 4.5 & 0.4 & 14 & 26 & 31.8 & 8.6 & 11406 \\
\hline 7 & 253 & 86 & 14.7 & 4.5 & 1.0 & 14 & 25 & 31.2 & 8.5 & 11331 \\
\hline 8 & 257 & 85 & 15.9 & 4.5 & 1.0 & 16 & 25 & 31.0 & 8.5 & 11256 \\
\hline 9 & 261 & 82 & 15.9 & 4.5 & 1.1 & 14 & 25 & 30.5 & 8.5 & 10655 \\
\hline 10 & 268 & 91 & 16.8 & 4.6 & 0.9 & 14 & 28 & 32.5 & 8.5 & 12006 \\
\hline 11 & 253 & 92 & 16.7 & 4.8 & 0.5 & 14 & 26 & 33.5 & 8.5 & 11856 \\
\hline 12 & 256 & 85 & 14.8 & 4.6 & 0.7 & 14 & 25 & 31.6 & 8.7 & 10355 \\
\hline 13 & 247 & 90 & 15.9 & 4.6 & 0.6 & 14 & 27 & 32.2 & 8.5 & 11706 \\
\hline 14 & 265 & 95 & 16.6 & 4.6 & 0.9 & 16 & 28 & 32.3 & 8.5 & 11406 \\
\hline
\end{tabular}


Ren, et al.

Table 12: Effects of different amounts of organic manure (chicken manure) on maize characters

\begin{tabular}{lcccccc}
\hline Handle & $\begin{array}{c}\text { Plant } \\
\text { height }(\mathbf{c m})\end{array}$ & $\begin{array}{c}\text { Alopecia } \\
\text { apex(cm) }\end{array}$ & $\begin{array}{c}\text { Ear row } \\
\text { number }\end{array}$ & $\begin{array}{c}\text { Ear } \\
\text { length(cm) }\end{array}$ & $\begin{array}{c}\text { Number } \\
\text { of spikes }\end{array}$ & $\begin{array}{c}100 \text { grain } \\
\text { weight }(\mathbf{g})\end{array}$ \\
\hline 1 & 291 & 1.9 & 16.4 & 17.1 & 619.7 & 38.1 \\
2 & 307.8 & 1.2 & 17.1 & 17.3 & 630.9 & 39.9 \\
3 & 307.4 & 1.3 & 17.2 & 17.6 & 623.6 & 38.6 \\
4 & 301 & 0.9 & 17.3 & 16.8 & 621.3 & 39.5 \\
5 & 310.0 & 1.0 & 16.9 & 17.5 & 633.0 & 40.3 \\
6 & 313.4 & 0.5 & 17.4 & 19.8 & 653.5 & 51.2 \\
7 & 303.0 & 0.8 & 16.8 & 17.4 & 595.1 & 38.9 \\
\hline
\end{tabular}

Table 13: Effects of different amounts of organic manure (chicken manure) on maize yield

\begin{tabular}{lccccc}
\hline $\begin{array}{l}\text { Material } \\
\text { code }\end{array}$ & \multicolumn{3}{c}{ Plot yield } & $\begin{array}{c}\text { Average yield } \\
\text { of district }\end{array}$ & $\begin{array}{c}\text { Hectare } \\
\text { yield }\end{array}$ \\
\cline { 2 - 4 } & I & II & III & 12.67 & 9744.3 \\
\hline $\mathrm{T}_{1}$ & 12.4 & 11.95 & 13.31 & 14.28 & 10985.7 \\
$\mathrm{~T}_{2}$ & 12.73 & 15.3 & 14.82 & 14.28 & 11317.1 \\
$\mathrm{~T}_{3}$ & 15.91 & 13.85 & 14.38 & 14.71 & 11231.9 \\
$\mathrm{~T}_{4}$ & 15.35 & 13.93 & 14.52 & 14.60 & 11590.3 \\
$\mathrm{~T}_{5}$ & 14.44 & 15.63 & 15.13 & 15.07 & 11945.4 \\
$\mathrm{~T}_{6}$ & 17.63 & 14.15 & 14.15 & 15.53 & 10839.5 \\
$\mathrm{~T}_{7}$ & 13.95 & 14.55 & 13.78 & 14.09 & \\
\hline
\end{tabular}

higher than those of Volfertile controlled release fertilizer $450 \mathrm{~kg} / \mathrm{hm}^{2}$. The ear diameter of Liaozhongjing compound fertilizer $600 \mathrm{~kg} / \mathrm{hm}^{2}$ is the largest, which is $5.33 \mathrm{~cm}$. The two-topdressing $525 \mathrm{~kg} / \mathrm{hm} 2$ treatment is the smallest, with $5.08 \mathrm{~cm}$. The worst is $0.25 \mathrm{~cm}$. The largest of 100 -grain weight is obtained with the treatment of Liaozhongjing compound fertilizer $450 \mathrm{~kg} / \mathrm{hm}^{2}$, which is $35.4 \mathrm{~g}$. The minimum is obtained with the treatments of Volfertile controlled release fertilizer 450 and $750 \mathrm{~kg} \mathrm{~kg} / \mathrm{hm}^{2}$ and twotopdressing $450 \mathrm{~kg} / \mathrm{hm}^{2}$, which is $34.2 \mathrm{~g}$. The worst is $1.2 \mathrm{~g}$.

From Table 10, it can be seen that, the corn yield of $\mathrm{CK}_{1-40}$ (two-topdressing $600 \mathrm{~kg} / \mathrm{hm}^{2}$ ) and A-40 treatment (Volfertile controlled release fertilizer $600 \mathrm{~kg} / \mathrm{hm}^{2}$ ) is significantly higher than that of other treatments. The corn yield of $\mathrm{CK}_{1-40}$ is the largest, which is $13925.1 \mathrm{~kg} / \mathrm{hm}^{2}$. The corn yield of $\mathrm{CK}_{1-30}$ (one topdressing $450 \mathrm{~kg} / \mathrm{hm}^{2}$ ) is the smallest, which is $11313.2 \mathrm{~kg} / \mathrm{hm}^{2}$. The two-topdressing is applied at the 2 stages of jointing and flare opening. It provides sufficient nitrogen fertilizer for the later stage of corn production, avoiding the phenomenon of removing fertilizer, and increasing the yield of maize. The yield of maize with A, B, C3 controlled release fertilizer and $\mathrm{CK}_{1}$ (once topdressing) increased first and then decreased with the increase of fertilizer amount (Chen et al., 2015). The corn yield of $\mathrm{CK}_{2}$ (two-topdressing) increased with the increase of the amount of fertilizer, thus increasing the yield of maize.

\section{Discussions of effects of fertilization depth and proportion} of different substrates on characters and yield of maize From Table 11, it can be seen that, the yield of 1 and 2 levels of different fertilization depths are better. The yield of three layers of fertilizer treatments is relatively high, and the 3 level of different fertilization depths shows poor performance. Different treatment designs have great influence on maize yield. The treatment combination with balanced design increased by $12 \%$ compared with the conventional fertilization method, and the treatment combination with unbalanced design reduced $9.2 \%$ yield compared with the conventional fertilization method. The different levels of fertilizer application rate varied with the depth of layer fertilization (Decaluwé et al., 2014).

According to the test results, different depth of fertilizer application is the main effect on yield. The interaction of the two factors is the secondary effect. The 1 and 2 levels $(0,8,16 \mathrm{~cm}$ and $0,10,16 \mathrm{~cm})$ of different depth of fertilizer application are conducive to yield increase. The 2 level (seed fertilizer: $20 \%$ urea, ammonium $40 \%$ phosphate, potassium sulfate, base fertilizer: $40 \%$ urea, $60 \%$ ammonium phosphate, potassium sulfate) of the factor of fertilization proportion is beneficial to the increase of yield of corn.

The effects of the 3 stages of the test were summarized (Wang, 2016). In the 3 levels of different levels of fertilization depth, the 1 level $(0,8,16 \mathrm{~cm})$ and 2 level $(0,10,16 \mathrm{~cm})$ are stable, and the 3 level $(0,12,16 \mathrm{~cm})$ has lower treatment effect. In the 3 levels of different levels of fertilization proportion, the treatment effect of the 2 level (seed fertilizer: 20\% urea, $40 \%$ phosphoric acid two amine, potassium sulfate, base fertilizer: $40 \%$ urea, $60 \%$ ammonium phosphate, potassium sulfate) and 1 level (seed fertilizer: 10\% urea, 30\% phosphoric acid two amine, potassium sulfate, base fertilizer: $50 \%$ urea, $70 \%$ phosphate two amine, potassium sulfate) is more stable. The stability of the 3 level (seed fertilizer: $30 \%$ urea, 50\% diammonium phosphate, potassium sulfate, base fertilizer: $30 \%$ urea, $50 \%$ diammonium phosphate, potassium sulfate) is poor.

\section{Discussions of effects of different amounts of organic manure (chicken manure) on characters and yield of maize}

From Table 12, it can be seen that, from 6 indexes of plant height, barren tip length, ear row number, ear length, grain number per ear, and 100-grain weight, the treatment 6 is 
Ren, et al.

Table 14: Effects of fertilization and density coupling on maize characters in different substrates

\begin{tabular}{|c|c|c|c|c|c|c|c|c|c|}
\hline $\begin{array}{l}\text { Factor } \\
\text { level }\end{array}$ & $\begin{array}{c}\text { Plant } \\
\text { height }(\mathrm{cm})\end{array}$ & $\begin{array}{c}\text { Ear } \\
\text { position }(\mathrm{cm})\end{array}$ & $\begin{array}{c}\text { Stem } \\
\text { diameter(mm) }\end{array}$ & $\begin{array}{c}\begin{array}{c}\text { Ear length } \\
(\mathrm{cm})\end{array} \\
\end{array}$ & $\begin{array}{c}\text { Spike } \\
\text { width }(\mathrm{cm})\end{array}$ & $\begin{array}{l}\text { Ear row } \\
\text { number }\end{array}$ & $\begin{array}{c}\text { Grain } \\
\text { number }\end{array}$ & $\begin{array}{l}\text { Alopecia } \\
\text { apex(cm) }\end{array}$ & $\begin{array}{l}1000 \text { grain } \\
\text { weight(g) }\end{array}$ \\
\hline $\mathrm{A} 1$ & $299.9 b B$ & $134.8 \mathrm{aA}$ & $22,75 a A$ & $17.0 \mathrm{aA}$ & $4,58 \mathrm{aA}$ & $13.8 \mathrm{aA}$ & $35.5 \mathrm{aAB}$ & $0.60 \mathrm{bB}$ & $360.0 \mathrm{aA}$ \\
\hline A2 & $309.8 \mathrm{aA}$ & 132.1aAB & $22.23 a A$ & $16.8 \mathrm{aA}$ & $4.48 \mathrm{bAB}$ & $13.1 \mathrm{bB}$ & $35.4 \mathrm{aAB}$ & $0.60 \mathrm{bB}$ & $371.9 \mathrm{aA}$ \\
\hline A3 & 298.1bB & $127.5 b B$ & $20.47 b B$ & $15.9 \mathrm{bB}$ & $4.44 \mathrm{bBC}$ & $12.9 \mathrm{bB}$ & $35.7 \mathrm{aA}$ & $1.00 \mathrm{aA}$ & $362.4 \mathrm{aA}$ \\
\hline A4 & 293.6bB & $119.0 \mathrm{cC}$ & $19.12 c C$ & $15.3 \mathrm{cB}$ & $4.34 \mathrm{cC}$ & 13.1bB & $34.0 \mathrm{bB}$ & $1.08 \mathrm{aA}$ & $358.4 \mathrm{aA}$ \\
\hline B1 & $290.0 b B$ & $118.0 \mathrm{dD}$ & $23.08 \mathrm{aA}$ & $17.4 \mathrm{aA}$ & 4.71aA & $14.0 \mathrm{aA}$ & $38.2 \mathrm{aA}$ & $0.38 \mathrm{dD}$ & 396.7aA \\
\hline B2 & 291.8cBC & $123.8 \mathrm{cCD}$ & $22.60 \mathrm{aAB}$ & $17.2 \mathrm{aA}$ & $4.60 \mathrm{bAB}$ & $13.9 \mathrm{aA}$ & 37.1aA & $0.43 d C D$ & $389.2 \mathrm{aAB}$ \\
\hline B3 & 295.7bcBC & $126.9 \mathrm{bcBC}$ & $21.53 \mathrm{bBC}$ & $16.4 \mathrm{bAB}$ & $4.49 \mathrm{cBC}$ & 13.6aA & $35.2 \mathrm{bB}$ & $0.67 \mathrm{cdBCD}$ & $367.6 \mathrm{bBC}$ \\
\hline B4 & $299.5 b B$ & 131.0bAB & $20.85 b c B C$ & $15.9 \mathrm{bcBC}$ & $4.41 \mathrm{cdC}$ & 13.6aA & $34.2 \mathrm{bcB}$ & $0.85 \mathrm{bcBC}$ & $360.0 \mathrm{bcC}$ \\
\hline B5 & $307.6 \mathrm{aA}$ & $132.5 \mathrm{abAB}$ & $20.03 c C$ & $15.4 \mathrm{cBC}$ & 4.33dCD & $12.4 \mathrm{bB}$ & $33.4 \mathrm{cdBC}$ & $1.09 \mathrm{bB}$ & $342.4 c C D$ \\
\hline B6 & $311.5 \mathrm{aA}$ & 137.7aA & $18.78 \mathrm{dD}$ & $15.1 \mathrm{cC}$ & $4.22 \mathrm{eD}$ & $11.9 \mathrm{bB}$ & $32.2 \mathrm{dC}$ & $1.52 \mathrm{aA}$ & 323.3dD \\
\hline
\end{tabular}

The difference between the lowercase letter and the English alphabet after the same column data is significant. The difference between the capital letters and the English letters indicates that the difference is very significant. Table 6 is the same.

better than other treatments. The plant height: $T_{6}>T_{5}>$ ,$T_{2}>, T_{3}>, T_{7}>, T_{1}$, the barren tip length: $T_{6}>T_{7}>, T_{4}$ $>, T_{5}>, T_{2}>, T_{3}>, T_{1}$, the ear row number: $T_{6}>T_{4}>, T_{3}^{4}$ $>, T_{2}>, T_{5}>, T_{7}>, T_{1}$, the ear length: $T_{6}>T_{3}>, T_{5}>, T_{7}$ $>, T_{2}>, T_{1}>, T_{4}$, the grain number per ear: $T_{6}>T_{5}>, T_{2}$ $>, T_{3}>, T_{4}>, T_{1}>, T_{7}$, the 100-grain weight: $T_{6}>T_{5}>$, $T_{2}>, T_{4}>, T_{7}>, T_{3}>, T_{1}$. The results show that treatment 6 is the best application rate of organic fertilizer, which can promote plant growth and development, enhance comprehensive resistance, and increase seed setting rate and grain capacity.

From Table 13, it can be seen that, the treatment 6 is more effective than other treatments in increasing production. The yield of corn increased by $12.74 \% \sim 22.59 \%$ compared with that of no organic manure. The result shows that organic fertilizer plays an important role in improving soil fertility and satisfying the nutrient requirements of maize during the whole growth period.

\section{CONCLUSIONS}

In this paper, from the 6 aspects of fertilization and application, fertilization and density coupling, fertilization and controlled release, fertilization level, fertilization depth and proportion, and the amount of organic manure (chicken manure), the character and yield of maize in the national Fluvo-aquic soil fertility and fertilizer efficiency monitoring base are tested and analyzed. Excel2003 and SPSS17.0 software is used for data processing and multiple comparisons are carried out by using Duncan's new multiple range test method. The conclusions are obtained as follows: (1) Effects of combined application of different substrates on character and yield of maize. From 7 treatments and 4 repeated tests, it can be known that, the application of NPK+ organic fertilizer (common amount and high amount) can optimize the characters of maize. The application of NPK+ high organic fertilizer can increase the yield of maize. There is no significant difference between other treatments; (2) Effects of fertilization and density coupling of different substrates on characters and yield of maize. From using two-factor split-plot design, 24 treatments and 3 repeated tests, it can be known that, under the condition of high fertilizer, the character of maize reached the best. The yield of maize is the highest for the density 60000 plants $/ \mathrm{hm}^{2}$ and the amount of fertilizer applied $\mathrm{N} 10.71 \mathrm{~kg}, \mathrm{P}_{2} \mathrm{O}_{5} 3.57 \mathrm{~kg}, \mathrm{~K}_{2} \mathrm{O}$ and $8.93 \mathrm{~kg}$ per $667 \mathrm{~m}^{2}$; (3) Effects of controlled release of different substrates on characters and yield of maize. From application of 6 controlled release fertilizer and setting 9 treatments, 3 controls, and 3 repeated tests, it can be known that, the characters of CRF V and CRFVI are the best. The proportion of $\mathrm{N}, \mathrm{P}$ and $\mathrm{K}$ of 4 kinds of controlled release fertilizers of CRF III, CRF IV, CRFV, and CRFVI is reasonable, and the control time is long. The one-off application of base fertilizer can meet the needs of maize growth and development for fertilizer nutrition. Therefore, compared with the traditional fertilization method, it saves time and effort, and can effectively increase the yield of maize; (4) Effects of fertilization level of different substrates on characters and yield of maize. By setting 15 treatments and 3 repeated tests, with 10 ears selected with the average ear method, it can be known that, the main reason for increasing grain yield is to choose a good fertilizer type, formulate reasonable fertilization level and fertilization method. It is suggested that A-40 treatment (Volfertile controlled release fertilizer $600 \mathrm{~kg} / \mathrm{hm}^{2}$ ) should be used in maize production process, and can be used as a base fertilizer to increase maize yield. The character of maize is the best by the treatment of the controlled release fertilizer of Agricultural University $450 \mathrm{~kg} / \mathrm{hm}^{2}$ and twotopdressing $600 \mathrm{~kg} / \mathrm{hm}^{2}$; (5) Effects of fertilization depth and proportion of different substrates on characters and yield of maize. Orthogonal test was carried out on two factors of maize depth and proportion of fertilizer application. The test results show that, under the same amount of fertilizer application, different levels of fertilizer depth and proportion combination will form 
different character types and yield results. The best combination method is seed fertilizer $20 \%$ urea, $40 \%$ ammonium phosphate and potassium sulfate applied to the subsurface $8 \mathrm{~cm}$, base fertilizer $40 \%$ urea, $60 \%$ phosphate, and potassium sulfate applied to the surface of $16 \mathrm{~cm}$. In addition, the 2 level of fertilization depth and the 1 level of fertilization proportion are better in the treatment, but the former can simultaneously improve the characters and yield of maize; (6) Effects of different amounts of organic manure (chicken manure) on character and yield of maize. Within certain fertilization level, maize yield increases with the increase of the amount of fertilization. Compared with no fertilization, the yield of maize is increased by $12.74 \% \sim 22.59 \%$. With the gradual increase of the amount of fertilizer, maize yield declined in the case of more than a certain level of fertilization. From the point of view of economic fertilization, the treatment 6 should be selected, that is, $35 \mathrm{~kg}$ fertilizer per plot. Treatment 6 is the best amount of organic fertilizer, which can promote plant growth and development, optimize maize character ratio and enhance comprehensive resistance. The amount of organic manure (chicken manure) 26923kg per hectare is the best amount of fertilizer, which can increase the yield of maize. The relationship between maize yield and fertilizer amount is preliminarily understood through experimental research, which provides reference for rational fertilization in maize production. Comprehensive analysis of these conclusions can be concluded that the proposed method can comprehensively and accurately analyze the effects of different substrates on the characters and yield of maize, which can promote rational fertilization and improve the quality and yield of maize.

\section{ACKNOWLEDGEMENT}

The National Key Research and Development Program of China (No. 2017YFD0101102-3); The Research and Development Program of Jilin Province (No. 20170307009NY).

\section{REFERENCES}

Abdur Razzak, M., M. A. Islam, M. H. Rahman, M. A. Sathi and M. Atikuzzamman. 2018. Screening of lentil germplasm against stemphylium blight by observing disease reaction in three different stages. Malays. J. Halal Res. 1(2): 15-18.

Ahamed, A. J., K. Loganathan, S. Ananthakrishnan, J. Ahmed and M. A. Ashraf. 2017. Evaluation of graphical and multivariate statistical methods for classification and evaluation of groundwater in alathur block, Perambalur district, India. Appl. Ecol. Env. Res. 15(3): 105-116.

Ahamed, M. S., H. Guo and K. Tanino. 2018. A quasi-steady state model for predicting the heating requirements of conventional greenhouses in cold regions. Inform. Process. Agric. 5(1): 33-46.

Al-zaqri, N., A. Alsalme, S. F. Adil, A. Alsaleh, S. G. Alshammari, S. I. Alresayes, R. Alotaibi, M. Al-Kinany and M. R. H. Siddiqui.
2017. Comparative catalytic evaluation of nickel and cobalt substituted phosphomolybdic acid catalyst supported on silica for hydrodesulfurization of thiophene. J. Saudi Chem. Soc. 21(8): 965-973.

Anzlovar, A., A. Krzan and E. Zagar. 2018. Degradation of plazno and phbvzno composites prepared by melt processing. Arab J. Chem. 11(3): 343-352.

Ashik, B. K., J. Shrestha and R. Subedi. 2018. Grain yield and yield attributing traits of maize genotypes under different planting dates. Malays. J. Sustains. Agric. 2(2): 06-08.

Atikuzzamman, M., M. A. Islam, M. Moniruzzaman and M. S. Islam. 2018. Vendors and consumers status and microbiological analysis of some common fast food items of different fast food restaurants in Barisal City. Malays. J. Halal res. 1(1): 17-21.

Barakat, A., S. Chuetor and F. Monlau. 2014. Eco-friendly dry chemomechanical pretreatments of lignocellulosic biomass: Impact on energy and yield of the enzymatic hydrolysis. Appl. Energy. 113(1): 97-105.

Brienzo, M., L. Tyhoda and Y. Benjamin. 2015. Relationship between physicochemical properties and enzymatic hydrolysis of sugarcane bagasse varieties for bioethanol production. $\mathrm{N}$. Biotechnol. 32(2): 253-262.

Chen, L., Q. Wang and K. Hirth. 2015. Tailoring the yield and characteristics of wood cellulose nanocrystals (CNC) using concentrated acid hydrolysis. Cellulose. 22(3): 1753-1762.

Danby, A. M., M. D. Lundin and B. Subramaniam. 2018. Valorization of grass lignins: Swift and selective recovery of pendant aromatic groups with ozone. Acs Sustain. Chem. 6(1): 71-76.

Daya, B. and K. Pant. 2017. Biomonitoring of wetland using macrophytes and macroinvertebrates. Malays. J. Sustain. Agric. 1(1): 11-14.

Decaluwé, R., D. Maes and A. Cools. 2014. Effect of peripartal feeding strategy on colostrum yield and composition in sows. J. Animal Sci. 92(8): 3557-3567.

Girtler, J. 2017. Features of load and wear of main propulsion devices on sea-going ships with piston combustion engines and their impact on changes in technical states of the systems. Pol. Marit. Res. 24(4): 57-66.

Huang, Z., P. Kumar and I. Dutta. 2014. Effects of microstructure and loading on fracture of $\mathrm{Sn}-3.8 \mathrm{Ag}-0.7 \mathrm{Cu}$ joints on $\mathrm{Cu}$ substrates with ENIG surface Finish. J. Electron. Mater. 43(12): 4485-4496.

Khaleel, C., N. Tabanca and G. Buchbauer. 2018. Alpha-terpineol, a natural monoterpene: A review of its biological properties. Open Chem. 16(1): 349-361.

Khan, M. M. H. 2018. Occurrence, distribution, host preference and damage severity of red pumpkin beetle - A review. Malays. J. Halal res. 1(1): 3-9.

Khila, S., B. Douh and F. Ruget. 2016. Application of STICS model in assessment of the effects of irrigation practices and soil properties on yield of a durum wheat (Triticum durum Desf.) cultivar in the irrigated area of Oued Rmel in Tunisia. Plant Pathol J. 5(6): 827-835.

Kim, N. Y., E. J. Jeon, S. H. Jung, S. J. Ahn, M. A. Park and J. S. Seo. 2018. Gene expression profiling and expression analysis of freshwater shrimp (Neocaridina Denticulata Denticulata) using expressed sequence tags and short-term exposure to copper. J. Environ. Biol. 39(1): 51-57.

Kylili, A., P. A. Fokaides, A. Ioannides and S. Kalogirou. 2018. Environmental assessment of solar thermal systems for the industrial sector. J. Clean. Prod. 176: 99-109.

Lidia, S., P. Kris and Z. Edward. 2014. The effect of organic mulches and mycorrhizal substrate on growth, yield and quality of gold Milenium 
apples on M.9 rootstock. Can. J. Plant. Sci. 94(2): 281-291.

Liu, H. and Z. Liu. 2010. Recycling utilization patterns of coal mining waste in China. Resour. Conserv. Recycl. 54(12): 1331-1340.

Liu, Z. 2017. Teaching reform of business statistics in college and university. Eurasia j. Math. Sci. Technol. Educ. 13(10): 6901-6907.

Lu, D., X. Sun and F. Yan. 2014. Effects of heat stress at different grain-filling phases on the grain yield and quality of waxy maize. Cereal. Chem. 91(2): 189-194.

McClements, D. J. 2018. Enhanced delivery of lipophilic bioactives using emulsions: a review of major factors affecting vitamin, nutraceutical, and lipid bioaccessibility. Food Funct. 9(1): 22-41.

Mo, S., Z. Li, K. Gou, L. Qin and B. Shen. 2018. Quantifying the effects of climate variability and direct human activities on the change in mean annual runoff for the Bahe river (Northwest China). J. Coast. Res. 34(1): 81-89.

Nazli, R. I., I. Inal and A. Kusvuran. 2016. Effects of different organic materials on forage yield and nutrient uptake of silage maize (Zea mays L.). J. Plant. Nutr. 39(7).

Nguyen, V. T., V. V. Quan and M. C. Bowyer. 2015. Effects of different drying methods on bioactive compound yield and antioxidant capacity of Phyllanthus amarus. Dry. Technol. 33(8): 1006-1017.

Oechsner, H. 2015. Effect of different pH-values on process parameters in two-phase anaerobic digestion of high-solid substrates. Environ. Sci. Technol. 36(2): 198-207.

Pavlović, M., A. Dimitrijević and D. Bezbradica. 2014. Dual effect of benzyl alcohol on $\alpha$-glucosidase activity: efficient substrate for high yield transglucosylation and non-competitive inhibitor of its hydrolytic activity. Carbohydr. Res. 87(387C): 14-18.

Robson, M. T., V. G. Dubrovskii and R. R. Lapierre. 2015. Conditions for high yield of selective-area epitaxy InAs nanowires on $\mathrm{SiO} x$ / $\mathrm{Si}(111)$ substrates. Nanotechnology. 26(46): 465301.

Salem, H. M., C. Valero and M. A. Muñoz. 2015. Short-term effects of four tillage practices on soil physical properties, soil water potential, and maize yield. Geoderma. 237-238: 60-70.

Sanchez Camacho, E. A. and M. M. Morales. 2017. Estimation of the volume of underground water for a coastal wetland. Rev. Int. Contam. Ambie. 33(SI): 65-76.

Shen, J., H. Tang and J. Liu. 2014. Contrasting effects of straw and straw-derived biochar amendments on greenhouse gas emissions within double rice cropping systems. Agric. Ecosyst. Environ. 188(4): 264-274.

Shin, E. C. and G. H. Jeong. 2014. Enhancement of carbon nanotube growth yield on Inconel 600 substrates through the surface pretreatments combining thermal annealing and plasma ion bombardment. Curr. Appl. Phys. 14(1): 8-12.

Urrea-López, R., R. I. D. de la Garza and J. I. Valiente-Banuet. 2014. Effects of substrate salinity and nutrient levels on physiological response, yield, and fruit quality of habanero pepper. Hortscience. 49(6): 812-818.

Wang, L. W. 2016. Study on the method of singular data classification retrieval and simulation. Comput. Simul. 33(5): 431-434.

Wang, Q., C. Lu and H. Li. 2014. The effects of no-tillage with subsoiling on soil properties and maize yield: 12-Year experiment on alkaline soils of Northeast China. Soil Tillage Res. 137(3): 43-49.

Zhang, L., J. E. Pemberton and R. M. Maier. 2014. Effect of fatty acid substrate chain length on Pseudomonas aeruginosa, ATCC 9027 monorhamnolipid yield and congener distribution. Process. Biochem. 49(6): 989-995. 